\title{
ZINC SUPPLEMENTATION REDUCES RECURRENT ACUTE LOWER RESPIRATORY INFECTION (ALRI)
}

Akhtar $\mathrm{K}^{1}$, Chowdhury $\mathrm{RB}^{2}$, Sultana $\mathrm{M}^{3}$, Yasmeen $\mathrm{S}^{4}$

\begin{abstract}
Introduction: Pneumonia is a frequent and serious human illness. In Bangladesh, Acute Lower Respiratory Infection (ALRI) is a major cause of death among young children. Childhood mortality can be reduced by $50 \%$ with detection and early treatment of illness with antibiotics and immunization. Zinc plays an important role in the optimal function of the immune system by reducing the risk, severity and duration of infectious diseases. Zinc supplementation improves health and cell mediated immunity.
\end{abstract}

Objectives: This study is aimed at documenting effect of zinc supplementation in preschool children on reducing ALRI.

Methods: This was a double blind random control trial interventional study among180 child, conducted at Comilla CMH, from January 2010 to December 2011. The children aged 6-60 months were selected randomly for comparison of effect of Zinc and Vitamin B-Complex on ALRI.

Results: In the study population, male to female ratio was 1.05:1. Baseline average age was 32 months and weight for height was $92 \%$ Of NCHS mean. It was found that $89 \%$ children completed immunization as per EPI schedule, the rest $11 \%$ were partially immunized. Twenty nine percent children had family history of Atopy. This study showed 15 episodes of ALRI in Zinc group (0.37episodes/child/year) compared to 47 episodes in the control B-Complex group (1.09episodes/child/year) during the six months follow-up. There was no association of ALRI with sex. The male female ratio in this respect was $1.07: 1$. In this study there was statistically significant and clinically important (67\%) reduction of episodes of ALRI in oral Zinc supplement group.

Conclusion: This finding strongly suggests that oral supplement of Zinc reduces episodes of ALRI in children.

Key-Words: ALRI, Pneumonia, Childhood mortality, Zinc-supplementation.

\section{Introduction}

Pneumonia has been a frequent and serious human illness throughout recorded history. In 1901 Sir William Osler stated "The most widespread and fatal of all acute diseases, Pneumonia is now Captain of the Death of Men". Almost 10 decades later, the prominence of pneumonia as a clinical entity remains the same, making the largest contribution to shortcoming of life expectencency ${ }^{1}$.

1. Lt Col Khaleda Akhtar, MBBS, DCH, FCPS, Graded Specialist in Paediatrics, CMH Savar, Savar Cantt. 2. Brig Gen Rehana Begum Chowdhury, MBBS, DCH, FCPS Adviser Specialist in Paediatrics, AFMC, Dhaka Cantt. 3. Lt Col Mahbuba Sultana, MBBS, DCH, FCPS, Graded Specialist in Paediatrics, CMH Chittagong, Chittagong Cantt. 4. Lt Col Sabina Yasmeen, MBBS, DCH, FCPS, Graded Specialist in Paediatrics, AFMI, Dhaka Cantt. 
Out of nearly 12.9 million deaths under 5 children about 4 million deaths annually are attributable to Acute Lower Respiratory Infection (ALRI) in the world and in developing countries they are associated with a third of all deaths in childhood ${ }^{2,3}$ In Bangladesh, ALRI are a major cause of death among young children. About $25 \%$ of the under 5 childhood deaths are attributable to $\mathrm{ALRI}^{4}$. Community-based trials have documented that this childhood mortality can be reduced by $50 \%$ with detection and early treatment of illness with antibiotics and immunization against measles and pertussis as carried according to immunization schedule $^{5,6}$. Therefore additional interventions to prevent ALRI are needed to complete the case-management approach in developing countries, as purely preventive programs alone, e.g. the EPI and pollution control, are inadequate ${ }^{7}$

The overall incidence of ARI is 5.5 episodes per child per year observed ${ }^{8}$. Despite the world-wide impact of ARI, or a combination of technical and operational reasons, it has often been neglected until recently, whereas diarrhoeal disease and malnutrition has received considerable attention ${ }^{7}$. As little is known about the changing pattern of etiological agents, a wide variety of viruses and bacteria are associated with pulmonary infection making it impossible to identify the specific etiological agent in each patient. Not only this, high prevalence of malnutrition, poverty and environmental deprivation are important contributors to the problem ${ }^{7}$.

Respiratory viruses were shown to impair mucociliary clearance and the functions of the polymorphonuclear neutrophils, alveolar macrophages and T-lymphocytes, thus allowing the pathogenic bacteria to invade the lower respiratory tract and start an infection. Increased incidence, severity and mortality of ALRI are associated with malnutrition and reduced immunological competency may be a mechanism for this association'. Even well nourished children of developing countries also suffer from ALRI and it is possible that they have impaired cell mediated immunity due to isolated Zinc deficiency ${ }^{10}$. Zinc plays an important role in the optimal function of the immune system by reducing the risk, severity and duration of infectious diseases like diarrhoea ${ }^{11}$. A sufficient zinc intake decreases the risk of respiratory infections and ensures a better ensures a better gut barrier, which protects against infections ${ }^{12}$. Zinc supplementation improves child health and improved cell mediated immune status $^{13,14}$. It is an essential element for health. The relative safety of this element, especially its lack of redox properties which, in contrast to iron and copper allows its utilization as an antioxidant and can stabilize cell membranes ${ }^{15,16}$. Because of Zinc's fundamental roles in cell growth and differentiation, the young growing organism is especially vulnerable to adverse effects from inadequate zinc ${ }^{17}$. So plasma zinc is used as a predictor of diarrhoeal and respiratory morbidity in children ${ }^{18}$. Therefore supplementation of zinc in deficient population especially preschool children should substantially reduce serious morbidity ${ }^{13,19}$. This study is aimed at determining effect of zinc supplementation on Acute Lower Respiratory Infection.

\section{Materials and Methods}

This observational study was carried out in Combined Military Hospital, Comilla during the period of January 2010 to December 2011. Study populations between 6 months to 5 years of both sexes were enrolled for the study. Undertook a double blind randomized control trial interventional study.Zinc group was designated as $\mathrm{A}$ and B-Complex group as B. Children having chronic illness like 
chronic renal disease, congenital or acquired heart disease and chronic neurological diseases like cerebral palsy were excluded from the study. Very sick unable to take oral zinc supplementation were also excluded.

A semi-structured questionnaire was prepared which included nutritional status, baseline ALRI and Immunization status. In regard of immunization, complete immunization indicate children were immunized according to age as per EPI schedule and partially immunized indicate those children who could not complete immunization though they have passed normal age of EPI schedule. ALRI were defined according to WHO criteria ${ }^{20}$. Pneumonia and Bronchiolitis were put under diagnosis of ALRI according to WHO guideline ${ }^{20}$. Anthropometric assessments were performed as baseline to exclude severe malnutrition. Weight for height was used for nutritional status assessment. Children whose weight for height is $-3 \mathrm{SD}$ or $<70 \%$ of the median of NCHS referred values (termed severe wasting) are severely malnourished.

Out of 180 children (90 in each group) 13 children didn't contribute, as some of them were missing during follow-up or excluded due to exclusion criteria. A child who was absent continuously for more than a month was considered terminated from the study.

Diagnosis of ALRI was made from history and clinical examination as followed:-

1.History like cough, breathing difficulty, running nose, fever, loss of appetite.

2.Clinical examinations like noisy breathing, respiratory distress (lower chest in drawing), and respiratory rate more than age specific and auscultatory findings.

Zinc group was coded as Group A and control (B-Complex) group was coded as Group B. $5 \mathrm{ml}$ of Zinc preparation contained $10 \mathrm{mg}$ elemental Zinc. The Zinc preparation was in the form of Zinc Sulphate and B-Complex was in the composition of $\mathrm{B} 1, \mathrm{~B} 2$ and B6. A fixed dose of $2 \mathrm{mg}$ per $\mathrm{kg}$ body weight per child was given daily for 2 months to all enrolled children. Children with baseline ALRI included in the study. After 2 months supplement, patient was reviewed at COPD once a month during 6 months for episodes of ALRI.

\section{Results}

Anthropometric assessments were performed at the baseline to exclude severe malnutrition. Baseline weight for height was $92 \%$ of NCHS mean as a whole. It was $93 \%$ and $91 \%$ of NCHS mean in Zinc supplement group and B-Complex group respectively. Nutritional status was well matched, with no significant $(p>0.05)$ difference between the groups. The average age of the children of Zinc supplemented group was 34 months while that of B-Complex supplemented group was 31 months. Age was well matched and there was no statistical significant difference $(\mathrm{p}>0.05)$ between two groups. In the study as a whole male female ratio was $1.07: 1$, in Zinc group the ratio was $1.05: 1$ and in B-Complex group it was 1.09:1. Sex was well matched, with no significant $(\mathrm{p}>0.05)$ difference between the groups. At baseline as a whole $22 \%$ children suffered from ALRI. Twenty percent in Zinc group and $23 \%$ in B-Complex group suffered from ALRI Baseline ALRI was well matched, with no significant $(\mathrm{p}>0.05)$ difference between them(Table-I).

Table-I: Comparison of baseline characteristics (mean \pm SD) of the two groups $(n=180)$

\begin{tabular}{|l|c|c|c|c|}
\hline & $\begin{array}{c}\text { Zinc } \\
\text { Supplement } \\
\text { Group (Group } \\
\text { A) (n = 90) }\end{array}$ & $\begin{array}{c}\text { B-Complex } \\
\text { Supplement } \\
\text { Group (Group } \\
\text { B)(n= 90) }\end{array}$ & $\begin{array}{c}\text { Total } \\
(\mathbf{n}=\mathbf{1 8 0})\end{array}$ & p \\
\hline Age (month) & $34.06 \pm 18.01$ & $30.92 \pm 16.48$ & $32.46 \pm 17.28$ & 0.19 \\
\hline Sex (Male/Female) & $46 / 44$ & $47 / 43$ & $93 / 87$ & 0.33 \\
\hline Baseline ALRI & $18(20 \%)$ & $21(23.33 \%)$ & $39(21.67 \%)$ & 0.59 \\
\hline Weight for Height* & $93.13 \pm 12.39$ & $90.59 \pm 11.84$ & $91.84 \pm 12.15$ & 0.15 \\
\hline
\end{tabular}

*\% of NCHS median

The study shows majority (89\%) of children completed immunization as per EPI schedule, while $11 \%$ children partially immunized. In zinc group $90 \%$ children, against $87 \%$ of B-Complex group children had complete immunization as per EPI schedule and the difference was not statistically $(\mathrm{p}>0.05)$ significant (Table-II). 
Table-II: Comparison of the immunization status of the study population between the two groups

\begin{tabular}{|l|c|c|c|}
\hline \multirow{2}{*}{$\begin{array}{l}\text { Immunization } \\
\text { status }\end{array}$} & \multicolumn{3}{|c|}{ Number of students (\%) } \\
\cline { 2 - 4 } & Zinc supplemen & $\begin{array}{c}\text { B-Complex } \\
\text { supplement }\end{array}$ & Total \\
\hline Complete & $73(90.12 \%)$ & $75(87.21 \%)$ & $148(88.62 \%)$ \\
\hline Partial & $08(9.88 \%)$ & $11(12.79 \%)$ & $19(11.38 \%)$ \\
\hline Total & 81 & 86 & 167 \\
\hline
\end{tabular}

$\chi 2=0.35, \mathrm{P}>0.5$ (not significant)

Table-III shows number of episodes of ALRI during 6 months follow-up. As a whole, 41(25\%) children suffered from one or more (total 62) episodes of ALRI. In Zinc supplement group $12(15 \%)$ children had total 15 episodes $(0.37$ episodes/child/year) of ALRI but in B-Complex supplement group 29(34\%) children had total 47 episodes (1.09 episodes/child/year) of ALRI.

Table-III: Number of episodes of ALRI during 6 months follow-up whole population

\begin{tabular}{|c|c|c|c|c|c|c|c|c|}
\hline \multirow{2}{*}{$\begin{array}{c}\text { Number o } \\
\text { episode of } \\
\text { ALRI }\end{array}$} & \multicolumn{6}{|c|}{ Number of children (Number of episodes) } & \multirow{2}{*}{\multicolumn{2}{|c|}{$\begin{array}{l}\text { Total number } \\
\text { of episodes }\end{array}$}} \\
\hline & \multicolumn{2}{|c|}{ Zinc Supplement } & \multicolumn{2}{|c|}{$\begin{array}{l}\text { BComplex } \\
\text { Supplement }\end{array}$} & \multicolumn{2}{|c|}{ Total } & & \\
\hline No & \multicolumn{2}{|c|}{$69(69 \times 0=00)$} & \multicolumn{2}{|c|}{$57(57 \times 0=00)$} & \multicolumn{2}{|c|}{$126(126 \times 0=00$} & \multicolumn{2}{|c|}{$0 \times 131=00$} \\
\hline One & $\begin{array}{c}10 \\
(10 \times 1=10)\end{array}$ & \multirow{3}{*}{$\begin{array}{c}12 \\
(15)\end{array}$} & $\begin{array}{c}13 \\
(13 \times 1=13)\end{array}$ & 29 & $\begin{array}{c}23 \\
(23 \times 1=23)\end{array}$ & \multirow{3}{*}{$\begin{array}{l}41 \\
(62)\end{array}$} & $1 X 23=23$ & \\
\hline Two & $\begin{array}{c}01 \\
(1 \times 2=2)\end{array}$ & & $\begin{array}{c}14 \\
(14 \times 2=28)\end{array}$ & $(47)$ & $\begin{array}{c}15 \\
(15 \times 2=30)\end{array}$ & & $2 \times 15=30$ & 62 \\
\hline Three & $\begin{array}{c}01 \\
(1 \times 3=3)\end{array}$ & & $\begin{array}{c}02 \\
(2 \times 3=6)\end{array}$ & & $\begin{array}{c}03 \\
(3 \times 3=09)\end{array}$ & & $3 \times 03=09$ & \\
\hline
\end{tabular}

Table-IV shows both Zinc group and control group had no statistically significant difference between particular sex groups with development of ALRI episodes during 6 months follow-up. As a whole, development of ALRI episodes in male and female were 32 and 30 respectively.

Table-IV: Sex distribution of the children who developed ALRI during 6 months follow-up between Zinc and B-Complex group

\begin{tabular}{|c|c|c|c|}
\hline \multirow{2}{*}{ Gender } & \multicolumn{3}{|c|}{ Number of episode of ALRI (\%) } \\
\cline { 2 - 4 } & Zinc Supplemer & $\begin{array}{r}\text { B-Complex } \\
\text { Supplement }\end{array}$ & Total \\
\hline Male & $06(40 \%)$ & $26(55.3 \%)$ & $32(51.6 \%)$ \\
\hline Female & $09(60 \%)$ & $21(44.7 \%)$ & $30(48.4 \%)$ \\
\hline Total & 15 & 47 & 62 \\
\hline
\end{tabular}

$\chi^{2}=1.07, P>0.5$ (not significant)
Fig-1 \& Table-V show that after intervention there was 39(44\%) recurrent and 23(56\%) non-recurrent episodes of ALRI as a whole. In Zinc supplementation group there were 5(17\%) recurrent episodes and 10(83\%) non-recurrent episodes and in control group there were 34(55\%)

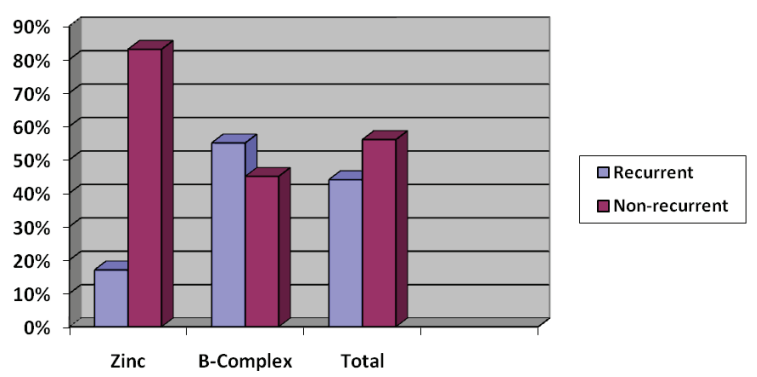

Fig-1: Association of recurrent attack of ALRI with Zinc or B-Complex supplement

Table-V: Association of recurrent attack of ALRI with Zinc or B-Complex supplement

\begin{tabular}{|l|c|c|c|}
\hline \multirow{2}{*}{$\begin{array}{l}\text { Recurrent } \\
\text { attack of }\end{array}$} & \multicolumn{3}{|c|}{ Number of episode } \\
\cline { 2 - 4 } ALRI & Zinc Supplement & $\begin{array}{c}\text { B-Complex } \\
\text { Supplement }\end{array}$ & Total \\
\hline Recurrent & $5(16.7 \%)$ & $34(55.2 \%)$ & $39(43.9 \%)$ \\
\hline $\begin{array}{l}\text { Non- } \\
\text { recurrent }\end{array}$ & $10(83.3 \%)$ & $13(44.8 \%)$ & $23(56.1 \%)$ \\
\hline Total & $15(100 \%)$ & $47(100 \%)$ & $62(100 \%)$ \\
\hline
\end{tabular}

$$
\chi 2=7.43, \mathrm{P}<0.01 \text { (Significant) }
$$

recurrent episodes and 13(45\%) non-recurrent episodes of ALRI. The difference is statistically significant $(\mathrm{P}>0.01)$.

\section{Discussion}

Present study showed male predominance in the study population. Male to female ratio was 1.07:1. But after intervention increased episodes of ALRI were not observed in a particular sex group. After intervention development episodes of ALRI in male and female were 32 and 30 respectively out of total 167 children under study. Male female ratio was 1.05:1. Even both Zinc and control (B-Complex) group showed no statistical significant difference between particular sex 
distributions with development of ALRI. This finding is different from the observation of McConnochie et al, who showed that episodes of LRTI in male is about double than those in female $^{21}$. This difference may be due to small sample size of our study.

This study shows 15 episodes of ALRI in Zinc group (0.37episodes/child/year) compared with 47 episodes in control group (1.09episodes/child/year). Sazawal et al showed that there were 0.19 episodes/child/year of ALRI in Zinc group compared with 0.35 episodes/child/year in the control group ${ }^{13}$.

Baseline weight for height was $92 \%$ of NCHS mean as a whole. Fauveau et al showed a small percentage of ALRI e.g. pertussis and measles related pneumonia, can be prevented with immunization ${ }^{3}$. Present study showed majority (89\%) of children completed immunization as per EPI schedule, in zinc group $90 \%$ and in control group $87 \%$. But no significant difference between the two groups for development of ALRI was found.

In our study we found that $41(25 \%)$ children had suffered from one or more episodes of ALRI. Twenty three $(14 \%)$ of them had one episode, $15(09 \%)$ of them had two episodes and the rest $3(02 \%)$ had three episodes. Zaman et al found that total was $16 \%^{8}$.

At baseline 38(21\%) children suffered from ALRI. Among them 18(47\%) children suffered from recurrent attack of ALRI during six months of follow up. Shah et al and Victora et al both showed previous history of ALRI increases the similar illness in later episodes ${ }^{20,22}$. In this study Zinc group had recurrent attack in $02(17 \%)$ children whereas in B-Complex group recurrence occurred in $16(55 \%)$ children. Therefore strong association of recurrent ALRI with B-Complex group than Zinc supplement group was found. In other word, Zinc supplementation had significantly reduced the recurrence of ALRI in the present study.

Zinc supplementation caused $67 \%$ reduction in the episodes of ALRI. A three month trial with Zinc-fortified bread reduced diarrhoea, illness and skin infection by $56 \%(\mathrm{p}<0.05 \%)$ among Turkish school children ${ }^{23}$. Sazawal et al in India demonstrated reduction of $45 \%$ of incidence of ALRI in Zinc supplemented group ${ }^{13}$. This study supports these findings.

\section{Conclusion}

Oral supplement of Zinc resulted in a significant reduction of ALRI in preschool children. These findings, along with documented effects of Zinc on ALRI indicate that interventions to improve Zinc intake deserve more attention as means to improve child immune status and ALRI.

\section{References}

1. Garenne M, Ronsmans C, Campbell H. The magnitude of mortality from acute respiratory infections in children under 5 years in developing countries. World Health Statistics Quarterly 1992; 45: 180-91.

2. Leowski J. Mortality from ARI in children under 5 years of age: Global estimates. World Health Statistics Quarterly 1986; 39: 138-44.

3. FauveauV, Stewart MK, Chakraborty J, et al. Impact on mortality of a community based programme to control acute lower respiratory tract infection. Bulletin of the World Health Organization 1992; 70: 109-16

4. Baqui AH, Black RE, Arifeen SE, et al. Causes of childhood deaths in Bangladesh: results of a nationwide verbal autopsy study. Bulletin of the World Health Organization 1998; 76: 161-71.

5. Sazawal S, Black RE. Meta-analysis of intervention trials on case management of ALRI in community settings. The Lancet 1992; 340: 528-33.

6. Koenig MA, Khan MA, Wojtyniak B, et al. Impact of measles vaccination on childhood mortality in rural Bangladesh. Bulletin of the World Health Organization 1990; 68: 441-47.

7. World Health Organization. A programme for controlling acute respiratory infection in children. Memorandum from a WHO meeting. Bulletin of the World Health Organization 1984; 62: 47-58.

8. Zaman K, Baqui AH, Yunus MD, et al. Acute Respiratory infection in children: A Community-based Longitudinal Study in Rural Bangladesh. Journal of Tropical Pediatrics 1997; 43: 133-37. 
9. Tupasi TE, Velmonte MA, Sanvictores MGE, et al. Determinations of morbidity and mortality due to acute respiratory infections: implications for intervention. The Journal of Infectious Diseases 1988; 157: 615-23.

10. Shakur MS, Malek MA, Bano N, Islam K. Zinc status in well nourished Bangladeshi children suffering from Acute Lower Respiratory Infection. Indian Pediatrics 2004; 41: 478-81.

11. Wintergerst, Maggini et al. Immune-Enhancing Role of Vitamin C and Zinc and Effect on Clinical Conditions. Ann Nutr Metab 2006;50:85-94.

12. Prassad. Zinc: Role in immunity oxidative stress and chronic inflammation. Curr Opin Clin Nutr Metab Care 2009; 12:646-52.

13. Sazawal S, Black RE, Jalla $S$, et al. Zinc Supplementation reduces the incidence of Acute Lower Respiratory in infants and preschool children: a double controlled trial. Pediatrics 1998; 102: 1-5.

14. Sazwal S, Jalla S, Majumder S, et al. Effect of Zinc supplementation on cell-mediated immunity and lymphocyte subsets in preschool children. Indian Pediatrics 1997; 34: 589-97.

15. Hambidge M. Human zinc deficiency. In: Zinc and Health; current status and future directions. Journal of Nutriton 2000; 130: 1344S-49S.

16. Shankar AH, Prasad AS. Zinc and immune function; the biological basis of altered resistance to infection. American Journal Clinical Nutrition 1998; 68 (Suppl): 447-63.
17. Hambidge M, Krebs N. Zinc, diarrhea and pneumonia. The Journal of Pediatrics 1999; 135: 661-4.

18. Bahl R, Bhandari N, Hambidge KM, et al. Plasma zinc as a predictor of diarrheal and respiratory morbidity in children in an urban slum setting. American Journal of Clinical Nutrition 1998; 68 (Suppl): 414-7.

19. Bhandari N, Bahl R, Taneja S, et al. Effect of routein Zinc supplementation on pneumonia in children aged 6 months to 3 years, randomized controlled trial in an urban slum. British Medical Journal 2002; 324: 1-5.

20. Shah N, Ramankutty V, Premilla PG, et al. Risk factors for severe pneumonia in South Kerala: A hospital based case control study. Journal of Tropical Pediatrics 1994; 40: 201-6.

21. McConnochie KM, Hall CB, Barker WH, et al. Lower respiratory tract illness in the first two years of life: Epidemiologic patterns and costs in a suburban paediatric practice. American Journal of Public Health 1988; 78(1): 34-9.

22. Victora CG, Fuchs SC, Flores JAC, et al. Risk factors for pneumonia among children in a Brazilian metropolitan area. Paediatrics 1994; 93(6): 977-85.

23. Bhutta ZA, Black RE, Brown $\mathrm{KH}$, et al. Prevention of diarrhoea and pneumonia by Zinc supplementation in children in developing country. The Journal of Pediatrics 1999; 135: 689-97. 